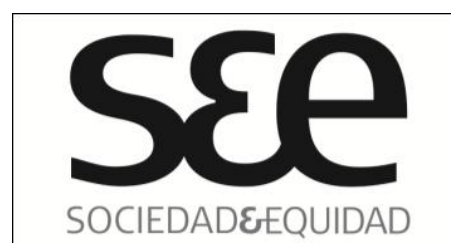

SOCIEDADEEQUIDAD

\section{Historia del Cuerpo III. Las mutaciones de la mirada. El siglo XX ( $\left.{ }^{1}\right)$}

History of the Body III. Mutations of the gaze. The twentieth century

\title{
RESUMEN
}

Historia del Cuerpo. Las mutaciones de la mirada. El siglo XX, es la tercera y última parte de esta verdadera enciclopedia del cuerpo que compilaron Corbin, Courtine y Vigarello. El cuerpo medicalizado, el cuerpo sexuado, el cuerpo ordinario, el cuerpo entrenado, el cuerpo danzante y el cuerpo desviado son algunas de las tantas manifestaciones corporales estudiadas en esta extensa obra. Asimismo, se analiza la relación entre cuerpo y experiencia de guerra y/o de campo de concentración. También se aborda el cuerpo en el cine. Esta obra invita al lector a realizar un recorrido por los grandes hitos de la Historia del siglo XX, pero a partir de la manera en que se grabaron en el cuerpo de las personas.

\section{ABSTRACT}

Historia del Cuerpo. Las mutaciones de la mirada. El siglo XX is the third and last part of this veritable encyclopedia of the body compiled by Corbin, Courtine and Vigarello. The medicalized body, sexed body, ordinary body, trained body, dancing body and deviated body are some of the many bodies studied in this extensive work. It also analyzes the relationship between body and experience of war and/or concentration camp. The body on film is addressed as well. This book invites readers to make a tour through the great landmarks of twentieth century history, focusing on the ways in which they were embodied by people.

PALABRAS CLAVES : Historia, cuerpo, siglo XX, medicina, deporte, guerra, sufrimiento. KEYWORDS :History, body, twentieth century, medicine, sport, war, suffering

\footnotetext{
${ }^{1}$ Corbin A., Courtine J. J. y Vigarello, G. (2006) Historia del cuerpo. Volumen III. Las mutaciones de la mirada. El siglo XX. Madrid: Taurus.

${ }^{2}$ El autor es Licenciado en Ciencia Política por la Universidad de Buenos Aires, Argentina. Es maestrando de la Maestría en Ciencias Sociales UNGS-IDES y Becario Doctoral de CONICET. Sus líneas de investigación son: socioantropología del deporte y el cuerpo.
} 


\section{s\&e \\ SOCIEDADEEQUIDAD}

Historia del Cuerpo. Las mutaciones de la mirada. El siglo XX compone el tercer volumen del compendio de libros dedicados a historizar el cuerpo que dirigieron Alain Corbin, Jean-Jacques Courtine y Georges Vigarello. Esta obra está compuesta por una breve introducción de Courtine y cinco grandes partes. Cada uno de esos apartados contiene capítulos dedicados a cuerpos diferentes. ¿De qué cuerpo hablamos cuando nos referimos a él? El enfoque general de la obra supone la existencia de una multiplicidad de cuerpos.

Uno de los cuerpos que cobró mayor relevancia en el siglo XX es el medicalizado. Los capítulos "El cuerpo frente a la medicina" e "Invención y puesta en escena del cuerpo genético", que componen la primera parte de este libro denominada "El organismo y los conocimientos", lo abordan en detalle. La primera mitad del siglo podría ser recordada como aquella época en que se creía haber eliminado las enfermedades del cuerpo. "Ya no sabemos estar enfermos", afirmaba Jean-Claude Beaune. La reducción de los tiempos del "estado enfermo" del cuerpo se logró mediante los nuevos tratamientos con antibióticos. El objetivo era claro: retrotraer lo más rápido posible ese cuerpo aquejado a su "estado natural". Un optimismo generalizado, aunque ingenuo, que auguraba la "abolición de las enfermedades" del cuerpo, chocó de lleno contra el retorno de las enfermedades infecciosas como la viruela y, en la década de 1980, contra la enfermedad infecciosa más devastadora de todas: el sida. El cuerpo se transformó también en un espacio de investigación médica. Se lo observa mediante radares, imágenes computarizadas y micro-cámaras. Podríamos preguntarnos si, a partir de esta mutación de la mirada, finalmente, ¿seguimos observando el mismo cuerpo?

La segunda parte de esta obra analiza otros cuerpos fundamentales en el siglo XX: el sexuado, el ordinario y el entrenado. A partir de la década de 1930, el cuerpo comienza a exhibirse en las playas: su bronceado demuestra unas "vacaciones perfectas" y cierta distinción de clase. Unos años más tarde, en 1946, se lanza al mercado un traje de baño femenino que causaría conmoción por su "impudor": la bikini. A la mayor exposición corporal se va a sumar, en la década de 1950, el descubrimiento de la píldora, que implicará una revolución sexual y cultural sin precedentes. Solo recién en la década de 1960 se hicieron realmente palpables todos esos cambios que venían operándose y que colocaron al cuerpo sexuado en el centro de la escena.

El cuerpo ordinario refiere a la aparición de formas corporales cada vez más similares. La modelización, la cosmética, la dietética y la cirugía plástica se transforman en prácticas frecuentes. Muchas pautas estéticas del siglo XIX perdieron su vigencia. Sin embargo, otras nuevas emergieron, sostenidas en el principio de la vida saludable pero también en el de la belleza, y resultaron tan constrictivas como las anteriores. 


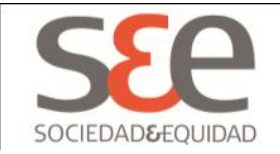

La relación entre cuerpo y deporte es abordada en el capítulo "Entrenarse". El número global de deportistas federados se multiplicó hasta por tres en el siglo XX. La política y el deporte también se enlazaron fuertemente: cada país comenzó a definir una política deportiva estatal y a asignar una partida presupuestaria para su promoción y sostenimiento. A partir de la segunda mitad del siglo XX, el deporte empezó a disociarse del entrenamiento. El cuerpo parece poder entrenarse sin realizar un deporte, ¿o es acaso un nuevo deporte el entrenamiento de gimnasio? A partir de la década de 1980, los gimnasios privados se multiplicaron por el mundo. El "momento de gimnasio" se consagra a la "vuelta sobre sí"; se trata de un espacio-tiempo que se dedica "para uno mismo".

El análisis de las "Desviaciones y peligros" del cuerpo conforma la tercera parte de la obra. A fines del siglo XIX, los "monstruos" eran exhibidos en las barracas y los circos. Sus grandes atracciones eran el hombre elefante, el enano o la mujer barbuda. La exposición monstruosa, al mismo tiempo que exotizaba esos cuerpos, cumplía una función social clara: recordar que ellos, los "monstruos", constituían una transgresión flagrante a la norma. Después de la Segunda Guerra Mundial, la exhibición de los "monstruos" de circo desapareció para siempre.

En ese siglo también se produjo una ligazón entre prácticas identificatorias y corporalidades. Este tema es abordado en "Identificar. Huellas, indicios y sospechas". En el siglo XIX se habían comenzado a estudiar los cráneos humanos con el fin de establecer correspondencias entre sus formas y los modos de comportamiento. La técnica antropométrica, desarrollada por Bertillon, fue ampliamente utilizada a principios de siglo. Sin embargo, el conjunto de operaciones técnicas requerido era complejo y costoso. Cayó finalmente en desuso cuando Galton descubrió el método de identificación basado en las huellas dactilares. Aunque a principios del siglo XXI este procedimiento identificatorio continúa vigente, ha ido siendo reemplazado por la identificación genética basada en el ADN.

La cuarta parte de la obra, "Sufrimientos y violencia", se dedica al cuerpo que ha sufrido la dramática experiencia de la guerra. A diferencia de antaño, las maneras de "portar" el cuerpo son otras en los combates del siglo XX. Hasta la segunda mitad del siglo XIX, el cuerpo del combatiente estaba erguido, ya fuera de pie o a caballo. Así se demostraba una actitud temeraria frente al enemigo y la muerte. En cambio, en los combates del siglo XX, el cuerpo se enfrenta escondido detrás de objetos, arrodillado o de "cuerpo en tierra". ¿Por qué se dieron estos cambios en las actitudes corporales bélicas? En buena medida debido a las innovaciones técnicas. A partir de principios del siglo XX, la industria bélica comenzó a desarrollar armas y municiones con una potencia de fuego mucho mayor que la que se utilizaba en las guerras anteriores. La "Gran Guerra" constituyó el teatro de operaciones en que este armamento se utilizó por primera vez.

El siglo XX también va a ser recordado, lamentablemente, por los campos de concentración nazis. Esta industria del exterminio implicaba, intrínsecamente, una mirada deshumanizante del otro y de su cuerpo. El cuerpo en el campo era una cosa, un 


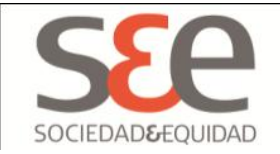

objeto. Se trató, sin duda, de la industria más perfectamente aceitada dedicada a masacrar cuerpos. Aun teniendo en cuenta el horror que nos produjeron Hiroshima y Nagasaki, los Gulag soviéticos o la guerra de Vietnam, como sostiene Primo Levi, ninguno de estos trágicos eventos ha superado el horror que todavía hoy nos produce la rememoración del Holocausto.

La quinta y última parte del libro trata sobre "La mirada y el espectáculo" del cuerpo. Espectáculo y deporte no tenían una relación directa a fines del siglo XIX. En las primeras décadas del siglo XX, en cambio, se vincularon estrechamente. La aparición del Tour de France, las Olimpiadas y el Mundial de Fútbol son los ejemplos más claros de ello.

Durante el siglo XX también se dio una transformación fundamental respecto a la manera de mirar esos espectáculos. Mientras que durante la primera mitad del siglo se concurría a los estadios, a partir de la segunda mitad la "televisación" consagró la intimidad del hogar como el espacio privilegiado para la mirada del espectáculo deportivo.

La primera proyección de cine data de finales del siglo XIX. A principios del siglo $X X$, el cine colocaba en pantalla las imágenes de los "monstruos" de la época. Sin embargo, el público ahora rechaza la proyección de esas "monstruosidades" reales. Se prefieren, en cambio, las ficciones monstruosas como King Kong, quien posee un cuerpo de gorila pero con alma de hombre. El cuerpo de la mujer también hace su aparición en la pantalla grande. La fabricación de un cuerpo femenino seductor comienza con Theda Bara y continúa con Greta Garbo, Marilyn Monroe o Brigitte Bardot. El retrato monstruoso no desapareció totalmente del cine; solo tuvo que readaptarse a las nuevas pautas de consumo cultural. Así, mediante la utilización de las nuevas técnicas de efectos especiales, la industria cinematográfica creó hombres-robots en Terminator, hombres-animales como El Pingüino de Batman o un ogro amistoso en Shrek.

La relación entre cuerpo y danza es tratada en "Escenas. El cuerpo danzante: un laboratorio de la percepción”. Cuando Loïe Fuller presentó por primera vez, a fines del siglo XIX, La danza serpentina conmocionó al público. El cuerpo danzante parece imposible de encontrar detrás de los velos. Se refugia, en gran medida, en una nueva experiencia de la visión. Los límites para el movimiento corporal desaparecen. El reconocido bailarín y coreógrafo estadounidense, Merce Cunningham, afirmó, a finales del siglo XX, que el único límite para el movimiento estaba dado por la propia imaginación.

Las artes visuales también cambiaron mucho durante el siglo XX. Este tema es tratado en "Visualizaciones". Aunque el origen de la fotografía data del siglo XIX, la nueva potencia de las técnicas fotográficas y de video permitió retratar al cuerpo de una manera distinta. Tres grandes registros visuales del cuerpo imperaron en el siglo XX: el del cuerpo mecanizado, el del cuerpo desfigurado y el del cuerpo bello. La imaginería del cuerpo mecanizado se abasteció de la práctica deportiva y de la gimnasia. A finales del siglo XX también se nutrió de los nuevos cuerpos de las prótesis técnicas y 


\section{SEe}

biotecnológicas. El cuerpo desfigurado en la guerra también ha sido registrado visualmente. Deberíamos preguntarnos: ¿hasta qué punto es éticamente correcta la estetización del horror de la guerra? El retrato del cuerpo bello fue la obsesión de todo el siglo. Esas imágenes se pueden observar en las artes populares, en las películas de Hollywood y en las publicidades de los productos de embellecimiento corporal.

El siglo XX implicó quiebres fundamentales con el pasado. Las guerras más devastadoras de la Historia, el descubrimiento de la píldora, la aparición de nuevas enfermedades y los profundos avances tecnológicos implicaron modificaciones sustanciales que también involucraron al cuerpo. Durante el siglo XX los pensadores también se empezaron a interrogar por el cuerpo: Freud, Husserl y Mauss son tan solo algunos de los más destacados. La invención del campo de estudios del cuerpo es también un legado que nos dejó ese siglo. Historia del cuerpo. Las mutaciones de la mirada. El siglo XX es una obra fundamental. Sin embargo, debido a la juventud de este campo de estudios, las mejores páginas sobre el cuerpo, en los albores del siglo XXI, aún deben escribirse.

\section{Referencia Bibliográfica}

Corbin A., Courtine J. J. y Vigarello, G. (2006) Historia del cuerpo. Volumen III. Las mutaciones de la mirada. El siglo XX. Madrid: Taurus. 